\title{
Rusça Yayımlanmış Türkiye Bibliyografyasında Yer Alan Türkiye Ermenileri Hakkında Literatür
}

\author{
The Literature about the Turkish Armenians in the Bibliography of Turkey \\ Published in Russian
}

\begin{abstract}
Şahin DOĞAN*
Özet: A. K. Sverçevskaya ve T. P. Çerman tarafından hazırlanmış olan Bibliografya Turtsii Literatura na Russkom Yazıke (1917-1975 gg.) adlı eser Sovyetler Birliği’nde yapılan Türkiye’ye ilişkin tarih, etnografya, edebiyat, filoloji vb. alanlarındaki çalışmaları ihtiva etmektedir. Bu çalışmada, Ermeni sorunu araştırmacıları için büyük bir önem arz ettiğini düşündüğümüz Sovyetler Dönemi’nde yapılan Türkiye Ermenilerine ilişkin çalışmalar yukarıda belirtilen eserden derlenerek Türk araştırmacıların bilgisine sunulmaktadır.
\end{abstract}

Anahtar sözcükler: Türkiye Bibliyografyası, Türkiye Ermenileri, Ermeni sorunu, Rusça literatür

Abstract: The bibliography prepared by A. K. Sverçevskaya and T. P. Çerman which is called Bibliografya Turtsii Literatura na Russkom Yazlke (1917-1975 gg.) contains studies concerning the history, ethnography, linguistics, literature and philology of Turkey which were published in the Soviet Union. In this studies concerning the Aramenians in Turkey are presented from the above mentioned bibliography which we think that great importance for researchers of the Armenian issue.

Keywords: Bibliography of Turkey, Turkish Armenians, Armenian issue, Literature in Russian

A. K. Sverçevskaya ve T. P. Çerman tarafından hazırlanmış olan Bibliografya Turtsii,Literatura na Russkom Yazıke (1917-1975) AN SSSR İnstitut Bostokovedeniya İzd.: Nauka, M. 1982. 1959 yılında yayınlanmış olan Türkiye Bibliyografyası (1917-1958) adlı eserin tekrar elden geçirilmesi ve önemli oranda tamamlanmasıyla yayınlanmıştır. Bibliyografya, Sovyetler Birliği'nde 1917'den 1975 yılına kadar Rusça olarak yayınlanmış Türkiye hakkındaki bilimsel ve popüler literatürü içermektedir.

Türkiye Bibliyografyası'nda, 1917-1975 yılları arasında Sovyetler Birliği’nde yapılan çalışmalara yer verilmiş olup Türkiye tarihi, etnografyası, din, edebiyat, filoloji vb. alanlarda yayınlanan toplam 15797 çalışma konularına göre tasnif edilmiştir.

Söz konusu bibliyografya içerisinde monografiler, dergilerden makaleler, külliyatlar, süreli yayınlar, broşürler, notlar, eserlerin özetleri (yazarlar tarafından yapılan: avtoreferat), eleştiri yazıları, Türk Edebiyatı'na ait eserlerin çevirileri ve aynı zamanda yabancı yazarların Rusça yayınlanmış çalışmaları bulunmaktadır. Gazete materyallerinden sadece edebî eserlerin çevirileri alınmıştır. Bu kitapta özel olarak Türkiye’yi konu edinmeyen fakat Türkiye hakkında bilgiler içeren çalışmalar da bulunmaktadır, bu durumda başlık veya bölüme ayrılmıştır veya parantez

\footnotetext{
* Okt. Dr., Akdeniz Üniv., Atatürk İlkeleri ve İnkılâp Tarihi Araş. ve Uyg. Merkezi, Antalya, sahindogan@akdeniz.edu.tr
} 
içerisinde Türkiye’yi ilgilendiren sayfalar gösterilmiştir.

Söz konusu Türkiye bibliyografisinde yer alan çalışmalar; Genel Çalışmalar ve Başvuru Eserleri, Rusya'da ve Sovyetler Birliği’nde Türkiye Araştırmaları'nın Tarihi, Seyahatler, Seyahat Notları, Türkiye Hakkında Notlar, Coğrafya, Toplum ve Etnografya, Devlet Yapısı, Siyasi Partiler, Tarih, Ekonomi, Kültür, Bilim ve Edebiyat başlıkları altında toplanmıştır (bk. Sverçevskaya, \& Çerman, 1982).

Bu çalışmada, Ermeni sorunu araştırmacıları için büyük bir önem arz ettiğini düşündüğümüz Sovyetler Dönemi’nde yapılan Türkiye Ermenileri, Ermeni sorunu vb. konulardaki Ermenilere ilişkin çalışmalar yukarıda belirtilen Türkiye Bibliyografyası'ndan derlenerek Türk araştırmacıların bilgisine sunulmaktadır. Ermenilerle ilgili Türkiye Bibliyografyası'nda yer alan Rusça literatür büyük oranda klasik Ermeni tezlerini yansıtmaktadır. Ancak, bu kaynakların incelenmesi hem Ermeni tarihçilerin bu tezlerinin yeterince anlaşılması ve hem de bu kaynaklarda bulunan önemli bilgilerin Türk bilim dünyasına kazandırılmaları açısından büyük önem arz etmektedir.

$\mathrm{Bu}$ nedenle bibliografyada bulunan Genotsit Arman (Ermeni Soykırımı), O Genotside Zapadnıh Arman (Batı Ermenilerinin Soykırımı Hakkında) vb. tarihsel gerçeklerle bağdaşmayan terimleri başlıklarında içeren çalışmalar da araştırmacıların dikkatine sunulmuştur.

\section{Türkiye Ermenileri ile İlgili Türkiye Bibliyografyasında Yer Alan Rusça Literatür}

1) Osmanskie zakonı v Zapadnoy Armenii (Batı Ermenistan'da Osmanlı Kanunları (Svod zakonov XVI-XVII vv.) Per., predisl.i komentariy A. H. Safrastyana i M. K. Zulanana. Rezume. Yerevan, AN ArmSSR, 1964, 124-127.

2) Zulanyan, M. K., Armeniya v pervoy polovine XVI v. (XVI. Yüzyılın İlk Yarısında Ermenistan) Avtoref.dis... kand. ist. nauk. L.,1959, 18 (Bib. sayfa 92).

3) Zulanyan, M. K., Armeniya v pervoy polovine XVI v. (XVI. Yüzyılın İlk Yarısında Ermenistan) M., “Nauka”, 1971, 126 -Bibliogr.: 118-125. (Bib. sayfa 92).

4) Ambaryan, A., İmperatorskiy zakon o polkah gamidie. (Hamidiye Alayları Hakkında İmparatorluk Kanunu) - "Vestnik arhivov Armenii". Yerevan, 1971, No:1, 81-94.

5) Valuyskiy, A. M., Novıe arhivnıe dokumentı o narnıh volneniyah v Maloy Azii v. period russkoy revolüttsii 1905-1907 gg (1905-1907 Rus Devrimi Döneminde Anadoluda’ki Halk Hareketleri Hakkında Yeni Arşiv Belgeleri), - “Kratkie soobşeniye İn-ta vostokovedeniya”, 1956, XXII, 88-91.

6) Genotsit arman v Osmanskoy imperii.(Osmanlı İmparatorluğu'nda Ermeni Soykırımı), Sb. dokumentov i materialov. Pod red. M.G. Nersisyana. Yerivan, AN ArmSSR, 1966, 562, Bibliogr.: 523-540.

7) Dokumentı mladoturetskogo komiteta o genotside zapadnıh arman v 1915-1916 gg. (19151916 Yıllarında Batı Ermenilerinin Soykırımı Hakkında Genç Türk Komitesinin Belgeleri), (Puplikatsiya. Predisl. R. G. Saakyana). - “İzvestiya” (AN ArmSSR). Obşest.nauki. Yerevan, 1965, No: 3, 73-86.

8) Mareskotti, L., Aldrovandi. Diplomatiçeskaya voyna. Vospominaniya i otrıvki iz dnevnika (1914-1918). (Diplomatik Savaş. Günlükten Hatıralar ve Pasajlar, 1914-1918), Per. s ital. Pod red. İ vstup. Statey B. Y. Şteyna. (M)., Gospolitizdat, 1944, 391.

9) Saakyan, R. G., Memuarı Naim-beya ob izbienii armyan. (Ermenilerin Katliamı Hakkında Naim Bey’in Hatıraları) - “Istoriko-filol. Jurnal”. Yerevan, 1965, No: 1, 101-107.

10) Arutünyan, G. M., Angliya i armyanskiy vopros v seredine 90 -h godov XIX veka. (İngiltere ve XIX. Yüzyılın 90’lı Yıllarının Ortalarında Ermeni Sorunu), - “Novaya i Noveyşaya İstoriya". 1959, No: 6, 92-97.

11) Arutünyan G. M., Reaktsionnaya politika angliskoy burjuazii v armyanskom voprose $v$ 
saredine 90-h XIX veka. (XIX. Yüzyılın 90’lı Yıllarının Ortalarında İngiliz Burjuvasının Ermeni Sorunundaki Reaksiyon Politikası), Abtorev. dis... kand.ist. nauk. M. 1954, 14.

12) Arutünyan, P. T., Osvoboditelnoe dvijenie armyanskogo naroda v pervoy çetverti XVIII veka. (XVIII Yüzyılın İlk Çeyreğinde Ermeni Halkı’nın Özgürlük Hareketi), (Otv.red.B.N. Zahoder i A.Z.İonisiani). M. izd-vo AH SSSR, 1954,304 s.

13) Badalyan, H. A., İz istorii sovmestnoy borbı narodov Zakavkazya protif sultanskoy Turtsii i zapadnıh kolonizatorov vo vtoroy polovine XIX veka, (XIX. Yüzyılın İlk Yarısında Transkafkasya Halklarının Türkiye’ye ve Batılı Sömürgecilere Karşı Ortak Mücadelesi Tarihinden),- “İzvestiya” (AN ArmSSR).Obşestv.nauki. Yerevan, 1961, No: 2, 43-48.

14) Bayramyan, L. A., İmperialistiçeskaya politika Anglii po otnoşeniyu k Zapadnoy Armenii v kontse XIX veka. (XIX. yüzyıl Sonunda Batı Ermenistan'a Karşı İngiltere’nin Emperyalist Politikası), Avtorev. dis...kand. ist.nauk. Yerevan, 1954, 19.

15) Barbi, A. V., strane ujasa.Muçenitsa Armeniya. (Dehşet Ülkesinde. Cefakar Ermenistan), Tiflis, izd. S. Melikova, 1919, 151.

16) Grigoryan, Z. T., Borba Anglii i Frantsii protiv osvobojdeniya Armenii iz-pod iranoturetskogo iga. (Ermenistan’ın İran ve Türkiye’nin Boyunduruğundan Kurtarılmasına Karşı İngiltere ve Fransa’nın Mücadelesi), - “Vopr.istorii”, 1952, No: 3, 19-33.

17) Davtyan, A. M., Taynaya tipografiya armyan-katolikov v Konstantinopole i ee deyatelnost.(Katolik Ermenilerin İstanbul'daki Gizli Tipografyası ve Faaliyetleri), Rezume. “İzvestiya” (AH ArmSSR). Obşestv. nauki.Yerevan, 1965, No: 1, 39.

18) İoannisyan, A. R., Borba Anglii i Frantsii protiv prisoyedineniya Armenii k Rossii. (Ermenistan'ın Rusya'ya Bağlanmasına Karşı İngiltere ve Fransa'nın Mücadelesi), "İzvestiya” (AN ArmSSR). Obşestv. nauki. Yerevan, 1953, No: 3, 49-62.

19) Kazaryan, G., zapadno-armyanskoe demokratiçeskoe dvijenie 1860-h godov. (1860’lı Yılların Batı Ermeni Demokratik Hareketi), Avtorev.dis kand.ist.nauk. Yerevan, 1959,30.

20) Kazaryan, G. M., Sotsialno-ekonomiçeskoe i politiçeskoe polojenie zapadnıh armyan v 1800-1870 gg. (1800-1870 Yılları Arasında Batı Ermenileri’nin Sosyo-Ekonomik ve Politik Durumları), Avtorev.dis...d-ra ist.nauk. Yerevan, 1968, 81.

21) Karamyan, K. N., Polojeniye zapadnıh armyan, "Armyanskiy Vopros" i mejdunarodnaya diplomatiya v posledney çetverti XIX veka i naçala XX veka. (Batı Ermenilerinin Durumu, "Ermeni Sorunu” ve XIX. Yüzyılın Son Çeyreği ve XX. Yüzyılın Başlarındaki Uluslar Arası Diplomasi), Avtorev.dis...d-ra ist.nauk. Yerevan, 1972, 111.

22) Kurginyan, Y. A., Armyanskaya problema v mejdunarodnıh otnoşeniyah 1876-1890 gg. (1876-1890 Yıllarında Uluslararası İlişkilerde Ermeni Sorunu), (Opıt issledovaniya voprosov natsionalno-osvoboditelnogo dvijeniya $\mathrm{v}$ Turetskoy imperii v period vostoçnogo krizisa 1875-1878, 1880-1882, 1894-1896 gg.) (1875-1878, 1880-1882, 1894-1896 Yıllarındaki Doğu Krizi Döneminde Türk İmparatorluğu’ndaki Milli Özgürleşme Sorunu İncelemesi) DAvtorev.dis...d-ra ist.nauk.M.,1969, 32 (Bib. Sayfa 106).

23) Kurginyan, Y. A., Armyanskiy vopros v vostoçnom krizise (1875-1878 gg.) (Doğu Krizinde Ermeni Sorunu, 1875-1878), “Uçenie Zapiski” (Mosk.obl.ped. in-t), 1967, T.174. Vseobşaya istoriya, vip.8, 61-67.

24) Kurginyan, Y. A., Armyanskiy vopros v San-Stefanskom dogovore 3 Marta 1878 g. (3 Mart 1878 San-Stefan Anlaşmasında Ermeni Sorunu) - “Uçenie Zapiski” (Mosk.obl.ped. in-t), 1967, T. 189. Vseobşaya istoriya, vip.9, 93-115.

25) Kurginyan, Y. A., Armyanskiy vopros na Berlinskom kongresse 1878 g. (1878 Berlin Konferansı’nda Ermeni Sorunu), “Uçenie Zapiski” (Mosk.obl.ped. in-t), 1968, T. 213. Vseobşaya istoriya, vip.10, 114-182. 
26) Kurginyan, Y. A., Borba armanskogo naroda protiv turetskogo iga v 1860-1870 gg. (18601870 Yıllarında Türk Boyundurluğuna Karşı Ermeni Halkının Mücadelesi), - "Uçenie Zapiski” (Mosk.obl.ped. in-t), 1965, T. 121. İst fakultet, vip. 5, 150-211.

27) Kurginyan, Y. A., Borba yevropeyskih derjav za razdel Blijnego i Srednego Vostoka v 7090-ye godı XIX v. (XIX. Yüzyılın 70-90’lı Yıllarında Batılı Devletlerin Yakın ve Orta Doğu’nun Bölünmesi için Verdikleri Mücadele),- “Uçenie Zapiski” (Mosk.obl.ped. in-t), 1971, T.301. Novaya i noveyşaya istoriya, vıp. 1.Sb.spets-kursov kafedr novoy i noveyşey istorii, 43-87.

28) Kurginyan, Y. A., Yevropeyskaya diplomatiya i armyanskiy vopros v 90-h godah XIX v. (XIX. Yüzyılın 90’lı Yıllarında Avrupa Diplomasisi ve Ermeni Meselesi) - "Uçenie Zapiski” (Mosk.obl.ped. in-t), 1968, T. 191. İstoriya SSSR, vip. 9, 197-224.

29) Ovnanyan, S. V., Armyano-bolgarskie svyazi i armyanskaya koloniya v Bolgarii vo vtoroy polovine XIX veka. (Ermeni-Bulgar İlişkileri ve XIX. Yüzyılın İkinci Yarısında Bulgaristan'daki Ermeni Kolonisi), Yerevan, AN ArmSSR, 1968, 380- Bibliogr. 344-359.

30) Ovnanyan, S. V., reznya armyan 1890-h godov i bolgarskaya obşestvennost. (1890 Yılları Ermeni Kıyımı ve Bulgar Kamuoyu) - “İstoriko-filol.jurnal”. Yerevan, 1965, No:2, 207-210.

31) Oganesyan, R. P., Natsionalno-osvoboditelnoe dvijenie zapadnı armyan v 70-80-h godah XIX veka i Karinskaya organizatsiya (XIX. Yüzyılın 70-80’li Yıllarında Batı Ermenileri’nin Milli Bağımsızlık Hareketi ve Karin Organizasyonu) “Paştpan Ayrenyats” (“Zaşita rodinı”). Avtoref. dis...kand.ist.nauk. Yerevan, 1964, 20.

32) Oganesyan, R. (P.), Podyom zapodnoarmyanskogo sotsialno-osvoboditelnogo dvijeniya posle russko-turetskoy voynı 1877-1878 gg.i vopros armyano-kurtsko-aysorskogo soglaşeniya. (1877-1878 Rus-Türk Savaşı’ndan Sonra Batı Ermenistan Sosyal ve Özgürlük Hareketi’nin Yükselişi ve Ermeni-Kürt-Aysor Antlaşması), (Rezüme.- "Vestnik arhivov Armenii”. Yerevan, 1965, No: 1, 188.

33) Pogosyan, A. M., İstoriya Zeytuna (1409-1921). (Zeytun Tarihi, 1409-1921), Aftoref.dis...d-ra ist. nauk. Yerevan, 1971, 52 (doktora tezi özeti).

34) Sarkisyan, Y. K., Administrativnaya i demografiçeskaya politika osmanskogo pravitelstva v Zapadnoy Armenii. (Batı Ermenistan'da Osmanlı Yönetimi’nin Yönetim ve Demografik Politikası)-V kn.: Stranı i narodı Blijnegoi Srednego Vostoka. V. Turtsiya. (Red.kol. O. G. İndjikyan, N. O. Oganesyan, G. M. Yeganiyan, Y. K. Sarkisyan (otv.red.). Yerevan, AN ArmSSR, 1970, 257-279.

35) Sarkisyan, Y. (K.), Armyanskiy vopros i velikie derjavı. (Ermeni Meselesi ve Büyük Devletler) - Lit.Armeniya”. Yerevan, 1965, No: 6, 63-74.

36) Sarkisyan, Y. K., Politika osmanskogo pravitelstvo v Zapadnoy Armenii i derjavı v posledney çetverti XIX i naçale XX v. (XIX. Yüzyılın Son Çeyreği ve XX. Yüzyılın Başında Batı Ermenistan'da Osmanlı Yönetimi’nin Politikası ve Devletler) (Otv.red.O.G. İndjikiyan). Yerevan, AN ArmSSR, 1972, 331.

37) Safaryan, M., "Natsionalnaya Konstitutsiya” zapadnıh armyan. (Batı Ermenileri'nin "Milli Anayasaları”), (Avtoref. Po kand.dis.) Yerevan, 1949, 28.

38) Siruni, A. Ç., Tanzimat i armyane. (Tanzimat ve Ermeniler), Rezüme.- "Istoriko-filol. Jurnal". Yerevan, 1966, No: 4, 66.

39) Taroyan, K. Z., Bejentsı Zapadnoy Armenii i ih polojeniye v kontse 90-h gg. XIX. V. i naçale XX v. (XIX. Yüzyılın 90’lı Yıllarının Sonu ve XX. Yüzyılın Başında Batı Ermenistan Göçmenleri ve Onların Durumları), Rezüme.- "Vestnik arhivov Armenii”. Yerevan, 1974, No: 3, 176.

40) Taroyan, K. Z., Narodnıye dvijeniya v Sasune i drugih rayonah Zapadnoy Armenii v 90-h 
godah XIX veka. (XIX. Yüzyılın 90’lı Yıllarında Sasun'da ve Batı Ermenistan'ın Diğer Bölgelerinde Halk Hareketleri), Avtoref.kand.ist.nauk. Yerevan, 1966, 23.

41) Martirosyan, A. G., Reznya armyan v Kilikyi v aprele 1909 goda i vopros ob otvetstvennosti mladoturok. (1909 Nisan'ında Kilikya'da Ermenilerin Kıyımı ve Genç Türklerin Sorumluluğu Meselesi Hakkında), (Rezüme.-V kn.:Stranı i Narodı Blijnego i Srednego Vostoka. V. Turtsiya. (Red. kol. O. G. İndjikyan, N. O. Oganesyan, G. M. Yeganiyan, Y. K. Sarkisyan (otv.red.). Yerevan, AN ArmSSR, 1970, 317-318.

42) Sovikyan, H. M., Mladoturetskaya revolutsiya i natsionalnıy vopros (Genç Türk Devrimi ve Milli Mesele), (Tezisı dis... kand.ist.nauk.). L. 1937, 13.

43) Akopyan, S. M., Genosit armyan v Osmanskoy imperii i otvetstvennost imperialistiçeskoy Germanii. (Osmanlı İmparatorluğu’nda Ermeni Soykırımı ve Emperyalist Almanya'nın Sorumluluğu) - “istoriko-filol.jurnal”. Yerevan, 1963, No: 1, 53-66.

44) Akopyan, S. M., Zapadnaya Armeniya v planah imperialistiçeskih derjav v period pervoy mirovoy voynı. (I. Dünya Savaşı Dönemi'nde Emperyalist Devletlerin Planlarında Batı Ermenistan), Avtoref. dis...kand. ist. nauk.Yerevan, 1964, 27.

45) Akopyan, S. M., Zapadnaya Armeniya v planah imperialistiçeskih derjav v period pervoy mirovoy voynı. (I. Dünya Savaşı Dönemi’nde Emperyalist Devletlerin Planlarında Batı Ermenistan), Yerevan, AN ArmSSR, 1967, 263 -Bibliograf.: 242-248.

46) Akopyan, S. M., Samooborona zapadnıh armyan v 1915-1916 gg. (1915-1916 Yıllarında Batı Ermenileri’nin Kendilerini Müdafaaları) Rezüme. “İzvestiya” (AN ArmSSR). Obşestv. nauki. Yerevan,1965, No: 4, 72.

47) Andrühin, M. N., Genosit v politike imperyalistiçeskih gosudarstv. (Emperyalist Devletlerin Politikasında Soykırım), M., “Znanie”, 1967, 48.

48) Verner E., Armyanskie ujası 1915/1916 g.-armyanskaya li vidumka? (1915-1916 Ermenilerin yaşadıkları (dehşeti) Ermeni uydurması mı? - "Vestnik arhivov Armenii”". Yerevan, 1974, No: 1, 137-143.

49) Gasparyan, A. A., Stranitsa iz istorii rezni armyan. (Ermeni Katliamı Tarihinden Bir Sayfa) (Rezüme.- "İzvestiya" (AN ArmSSR). Obşestv. nauki. Yerevan. 1965, No: 5, 80.

50) İstyagin, L. G., Ekspansiya germanskogo imperializma v Turtsii i russko-germanskie protivoreçiya po armyanskomu voprosu (1912-1914 gg.) - (Alman Emperyalizminin Türkiye’de Yayılması ve Ermeni Meselesinde Rus-Alman Çelişkileri), İz istorii agresivnoy vneşney politiki germanskogo imperializma. (Alman Emperyalizminin agresif dış politika tarihinden) Sb. statey. M. 1959, 3-53.

51) Kirakosyan, Dj. Zapadnaya Armeniya v godı pervoy mirovoy voynı. (I. Dünya Savaşı Yıllarında Batı Ermenistan), (Pod. Red.M.G.Nersisyana) yerevan, izd-vo Yerevansk.un-ta, 1971, 477.

52) Kirakosyan, Dj., Mejdu-nerodnıy imperializm i turetskaya politika istrebleniya armyan. (Uluslararası Emperyalizm ve Türkiye'nin Ermenileri Yok Etme Politikası), Rezüme. "İzvestiya" (AN ArmSSR). Obşestv.nauki. Yerevan, 1965, No: 4, 98-99.

53) Kirakosyan, D. S., Pervaya mirovaya voyna i zapıdnıe armyane (1914-1918). (I. Dünya Savaşı ve Batı Ermenileri (1914-1918), Avtoref. dis...d-ra. ist. nauk. Yerevan, 1965, 81.

54) Muradyan, A., Tragediya i borba armyan Tarona v 1915 godu. (1915 yllında Taron Ermenileri’nin Trajedisi ve Mücadelesi), Rezüme. -“Vestnik arhivov Armenii”. Yerevan, 1968, No: 2, 214.

55) Nersisyan, M.G., genotsit zapadnıh armyan v 1915 godu. (1915 Batı Ermenileri'nin Soykırımı). - "İstoriko-filol.jurnal”. Yerevan, 1965, No: 2, 55-60.

56) Stepanyan, St., Armeniya v politike imperialistiçeskoy Germanii (konets XIX-naçalo XX 
veka). (Emperyalist Almanya’nın Politikasında Ermenistan (XIX. Yüzyılın sonu- XX. Yüzyılın başı), Yerevan, “Aystan”, 1975, 243-Bibliogr.: 227-242.

57) Stepenyan, S., genotsit armyan v Osmanskoy imperii v period pervoy mirovoy voynı i prestupnoe posobniçestvo kayzerovskoy Germanii. (I. Dünya Savaşı Döneminde Osmanlı İmparatorluğu'nda Ermeniler'in Soykırımı ve Kayzer Almanyası'nın Suç Ortaklığı),“Vestnik arhivov Armenii”. Yerevan. 1973, No: 1 (35), 197-207.

58) Stepanyan, S. S., İmperialistiçeskie ustremleniya kayzerovskoy Germanii po otnoşeniyu k Zapadnoy Armenii nakanune pervoy mirovoy voynı. ( I. Dünya Savaşı Dönemi’nde Kayzer Almanya'sının Batı Ermenistan'a Emperyalist Yönelimleri) - "Vestnik obşsestv.nauk" (AN ArmSSR). Yerevan, 1972, No: 7, 48-57.

59) Armyano-russkie otnoşeniya v pervoy treti XVIII veka. (XVIII. Yüzyılın İlk Yarısında Ermeni-Rus İlişsileri), Sb. dokumentov. T. II., ç. I-II. Pod red. A. İoannasyana. (Sost. P. T. Arutünyan, S. A. Ter-Avakimov, V. A. Akopyan). Yerevan, AN ArmSSR, 1964-1967. Ç.I, 1964, 396, Ç.II, 1967, 420 s.

60) Rossiya, Turtsiya i Armeniya (Rusya, Türkiye ve Ermenistan), (Po dokumentam arhiva minesterstva inostrannıh del pravitelstva Kolçaka).- "Vestnik NKID”, 1921, No: 1-2, 57-63.

61) Safrastyan, A. H., Turetskie istoçniki ob Armenii, armyanah i drugih narodah Zakavkazyah. (Ermenistan, Ermeniler ve Diğer Transkafkasya Halkları Hakkındaki Türk Kaynakları) T. III. Yerevan, AN ArmSSR, 1961-1964.

62) Kaftaryan, S. M., Rossiya i armyano-turetskie otnoşeniya ot Turkmançayskogo dogovora do Berlinskogo kongressa (1828-1878). (Türkmençayı Anlaşması'ndan Berlin Konferansı'na Kadar Rusya ve Ermeni-Türk İlişkileri (1828-1878) Avtoref. Dis...d-ra ist.nauk. Kiev, 1953, 44.

63) Hacik, A. B., Armeniya v russko-turetskoy voyne (1877-1878 gg.) (Rus-Türk Savaşında (1877-1878) Ermenistan), Yerevan, “Aypetrat”, 1959, 155.

64) Armyanskiy vopros na Lozannskoy konferentsii. (Lozan Konferansı'nda Ermeni Meselesi), İzbleçeniyeizprotokolov. Per. M. T., spredisl. P. Makintsiana. Tiflis, Zakniga,1926, VIII, 36.

65) Jeltyakov, A. D., Antifrantsizskoe vosstanie v Maraşe v 1920 godu (1920 yılında Maraş’ta Fransızlara Karşı Ayaklanma), (K istorii antiimperyalistiçeskoy borbı v goradah YugaVostoçnoy Anatolii v 1919-1921gg.) (1919-1921 yıllarında Güneydoğu-Anadolu Şehirlerinde Anti-emperyalist Mücadele Tarihine) - Uçenıe zapiski Leningr. gos. Un-ta”, 1962, No: 304. Seriya vostokovedç. nauk. vip. 14, 30-42.

66) K sogleşeniyu o Kilikii. (Kilikya Hakkındaki Antlaşma) - “Vestnik NKID”, 1921, No: 3-4, 45-48.

67) Novoesrajeniya v Kilikii. (Kilikya’da Yeni Meydan Muharebesi)-“Bül.NKID”,1921, No: 81, 29.

68) Politika Frantsii v Kilikii. (Fransa’nın Kilikya’daki Politikası) “Bül. NKID”, 1920, No: 44, 44-45.

69) Polojenie v Kilikii. (Kilikya’da Durum) - “Bül.NKID”, 1920, No: 19, 31-33; 44.

70) Polojenie v Kilikii. (Kilikya’da Durum) - “Bül.NKID”, 1921, No: 89, 54-55.

71) Protest konstantinopolskih armyan. (İstanbul Ermenileri’nin Protestosu) - “Bül.NKID”, 1921, No: 57, 18.

72) Terror v Kilikii. (Kilikya’da Terör) - “Bül.NKID” 1920, No: 24, 25-26.

73) Frantsiya na Vostoke- (Fransa Doğu’da), “Bül.NKID”, 1921, No: 57, 5.

74) Frantsuzı v Maloy Azii. (Fransızlar Küçük Asya’da) - “Bül.NKID”, 1920, No: 4, 12-13.

75) Frantsuzı evakuriruyut Kilikiyu. (Fransızlar Kilikya’yı Tahliye Ediyorlar) - “Bül.NKID”, 1920, No: 24, 26.

76) Avanesov, S. S., Polojenie natsionalnıh menşinstv v Turtsii. (Türkiye’de Azınlıkların Du- 
rumu), Yerevan, AN ArmSSR, 1963, 170.

77) Akopov, A., Kurdskiy vopros i daşnaki. (Kürt Meselesi ve Taşnaklar) - "Bolşevik Zakavkazya". Tifilis, 1931, No: 2, 37-42.

78) Arzumanyan, M. V., Oktyabrskaya revolutsiya i zapadnaya Armeniya. (Ekim Devrimi ve Batı Ermenistan), Rezüme - "Vestnik arhivov Armenii". Yerevan. 1967, No: 3, 223-224.

79) Armyne v Konstantinopole. -(İstanbul’da Ermeniler),” Jizn natsionalnestey “, 1923, kn. 3-4, 214.

80) Politika ve SSSR Ç.I-II. M.-L., Gosizdat, 1928-1929. Ç.I, 1928, 447, Ç.II, 1929, 434.

81) Gasratyan, M. A., Natsionalnıy vopros v Turtsii (1919-1939). (Türkiye’de Ermeni Meselesi, 1919-1939), Avtoref. dis,... kand. ist. nauk.M., 1956, 15.

82) Djivilegov, A. K., Armeniya i Turtsiya. (Ermenistan ve Türkiye) Stenogr. publ.leksii.M., "Pravda", 1946, 16.

83) Natsionalnıe menşinstva posle mirovoy voynı. (I. Dünya Savaşı Sonrası Azınlıklar),“Mejdunar. Jizn”, 1925, No: 1, 18-43.

84) Safaryan, M., Natsionalnaya konstitutsiya zapadnıh armyan (Batı Ermenileri'nin "Milli Anayasası”) (Avtoref, dis...kand.ist. nauk). Yerevan, 1949, 28.

85) Torosyan, Ş. T., Obşestvenno-politiçeskaya jizn kilikiyskih armyan v 1919-1920 gg. (19191920 yıllarında Kilikya Ermenilerinin Toplumsal ve Politik Hayatı), Avtoref. dis....kand. ist.nauk. Yerevan, 1969, 25.

86) Balikyan O.; Evoyan V.; Sarkisyan G., Ekspansionistskaya Politika Turtsii v Armenii (Türkiye’nin Ermenistan’da Sömürü (Yayılma) Politikası). Yerevan, 1971, No:1, 31-52.

87) Armeniya i Mustafa Kemal (Ermenistan ve Mustafa Kemal) - “Bül. NKID”, 1921, No: 57, 16.

88) Armyano-kemalistkoeperemirie. (Ermeni-Kemalist Ateşkesi) - “Bül.NKID”,1921, No:57, 16.

89) Badalyan, H. A., Zakavkaze v period germeno-turetskoy interventsii. (Alman-Türk Askeri Müdahalesi Dönemi’nde Transkafkasya ) Avtoref. dis,...d-ra ist.nauk.Yerevan, 1965, 68.

90) Boşnagyan, S. A., Turetskaya agressiya v Zakavkaze i borba trudyaşihsa Armenii protiv zahvaççikov i ih prislujnikov v 1918 g. (1918 yılında Transkafkasya'da Türk Saldırganlığı ve İşgalcilere ve Onların Uşaklarına Karşı Ermenistan Emekçilerinin Mücadelesi), Avtoref.dis. ...kand. ist. nauk.Yerevan, 1954, 21.

91) Vartanyan, S., Pobeda sovetskoy vlasti v Armenii (Sovyet Yönetimi’nin Ermenistan'daki Zaferi), Yerevan, Gosizdat Armenii, 1959, 523. Sm: Daşnako-kemalistkaya voyna osenyu 1920 goda, 297-321.

92) Galoyan, G., Borba za sovyetskuyu vlast v Armenii. (Ermenistan’da Sovyet Egemenliği için Mücadele), M., Gospolitizdat, 1957, 251.

93) Gugovskiy, A., Pobeda sovetskoy vlasti v Armenii v 1920 godu. (1920 yılında Sovyet Yönetimi’nin Ermenistan'daki Zaferi) - “İstorik-marksist”, 1940, kn.11, 8-17.

94) Drujba Turtsii s Rossiey. (Türkiye’nin Rusya’yla Dostluğu) - “Bül.HKID”, 1921, No: 77, 28.

95) K Armyano-turetskim otnoşeniyam. (Ermeni-Türk İlişkilerine) - “Jizn natsionalnestey”, 1922, No: 8, 13-14.

96) Kandişev, A. B., İnterventsiya i grajdanskaya voyna v Zakavkaze. (Transkafkasya’da Askeri Müdahale ve İç Savaş ), M., Voyenizdat, 1960, 510-Bibliogr.: 446-453.

97) Kazandjyan, R. V., K voprosu o diplomatiçeskih otnoşeniyah mejdu RSFSR i daşnakskoy Armeniyey nakanune armyano-turetskoy voynı 1920 g. (1920 Ermeni-Türk savaşı Döneminde RSFSR ve Taşnak Ermenistanı Arasındaki Diplomatik İlişkiler Meselesi) - ” Vestnik arhivov Armenii”. Yerevan, 1965, No: 2, 190-206.

98) Karapetyan, S. H., Proval popıtki organizatsii novogo pohoda anglo-amerikanskih imperialistov protiv Sovetskoy Rossii i Zakavkazya v 1920-21. (1920-21 yıllarında Sovyet 
Rusya’sına ve Transkafkasya’ya karşı İngiliz-Amerikan Savaş Girişimlerinin Başarısızlığı) "İzvestiya” (AHArmSSR). Obşestv.nauki. Yerevan, 1953, No: 9, 37-52.

99) Tonoyan, G. G., Naşestvie turetskih imperialistov i armyano-turetskaya voyna 1918 goda. (Türk Emperyelistleri'nin İstilası ve 1918 Ermeni-Türk Savaşı), (Rezüme.-Sbornik nauçnometodiçeskih trudov (Arm. Gos. İn-t fizkulturı). Vıp. V. Yerevan, 1959, 42-43.

100) Turki i Armeniya. (Türkler ve Ermenistan), - “Bül.HKID”, 1920, No: 45, 35-36.

101) Turtsiya i Armeniya. (Türkiye ve Ermenistan), - “Bül.HKID”, 1920, No: 48, 28.

102) Haçaturyan R., Krah Turetskoy agressii v Sovyetskoy Armenii v 1920-1921 godah. (19201921 yıllarında Sovyet Ermenistan’ında Türk Saldırganlığının İflası), (-“İzvestiya” (AN ArmSSR). Obşestv.nauki. Yerevan, 1952, No: 8, 59-85.

103) Elçibekyan, A., Materialı k istorii turetsko-daşnakskih otnoşeniy v kontse 1920 i naçale 1921 g. (1920 Yılının Sonu 1921 Yılı Başlarında Türk-Taşnak İlişkileri Tarihi ile İlgili Materyaller), - “İzvestiya” (AN ArmSSR). Obşestv.nauki. Yerevan, 1951, No: 9, 61-68. 